\title{
La tejeduría indígena en la Patagonia meridional argentina. Análisis de las razones de su adopción por los aónik'enk y planteamiento de una nueva propuesta explicativa
}

\author{
Patricia María MÉNDEZ \\ Facultad de Ciencias Humanas, Universidad Nacional del Centro de la Provincia de Buenos Aires \\ pmendez@aibr.org
}

Recibido: 8 de abril de 2011

Aceptado: 30 de junio de 2011

\section{RESUMEN}

Partiendo del análisis de las hipótesis vigentes sobre las razones por las cuales los aónik'enk (Patagonia meridional argentina) adoptaron la tejeduría, se cotejan a continuación esas hipótesis con información empírica histórica, lo que permite concluir que las mismas no se pueden hacer extensivas a todas las agrupaciones aónik'enk. En búsqueda de hipótesis alternativas se realiza un estudio de los textiles que confeccionaron y usaron esas agrupaciones empleando información histórica, etnográfica y arqueológica. A partir de esos resultados se propone la adopción de una perspectiva simbólica que permita superar el determinismo material de las hipótesis actuales y formular explicaciones satisfactorias al respecto.

Palabras clave: Patagonia argentina, aónik'enk, textilería, explicaciones materialistas, perspectiva simbólica.

The Indigenous Weaving in the Southern Patagonia, Argentina. Analysis of the Reasons for its Adoption by the Aónik'enk and Posing of a New Explanatory Proposal

\begin{abstract}
First, we analyze the assumptions of the current hypotheses on the reasons why Aónik'enk (Southern Argentinean Patagonia) took the weaving. Following these assumptions are compared with historical empirical data. This allows to conclude that they cannot be extended to all Aónik'enk groups. In search of alternative hypotheses, a study of textiles made and used by these groups using historical data, ethnographic and archaeological is performed. From these results we propose the adoption of a symbolic perspective to overcome the material determinism of the current hypotheses and make satisfactory explanations about it.
\end{abstract}

Key words: Argentinean Patagonia, Aónik'enk, weaving, materialistic explanations, symbolic perspective.

Sumario: 1. Introducción. 2. Hipótesis vigentes sobre la adopción de la textilería por los aónik'enk. 3. Análisis de la información empírica sobre la presencia de la práctica textil entre los aónik'enk. 4. Los tejidos que realizaron y los usos que les dieron. 5. Síntesis, conclusiones y propuesta. 6. Agradecimientos. 7. Referencias bibliográficas.

\section{Introducción}

La bibliografía científica ha empleado las denominaciones «aónik’enk» o «tehuelches meridionales» para identificar a diversos grupos indígenas de las regiones más australes de la Patagonia argentina continental. Tales denominaciones se otorgaron 
sobre la base de rasgos lingüísticos y ubicaciones geográficas comunes que permitieron considerarlos una única agrupación. Sin embargo, el registro de espacios territoriales que serían exclusivos de parcialidades más reducidas, ha llevado a plantear la existencia de subdivisiones o grupos diferenciados entre los aónik'enk (Vignati s/f; Escalada 1949; Casamiquela 1965; Martinic 1995).

Según Casamiquela (1965), entre mediados del siglo XVII y finales del siglo XIX, estos grupos estaban geográficamente ubicados entre el estrecho de Magallanes y el río Chubut, y entre la cordillera de los Andes y el océano Atlántico. En ese espacio, este autor distinguió dos grandes parcialidades: los «Aónikenk o Tehuelches Meridionales Boreales» ocupaban el territorio comprendido entre el río Santa Cruz y el río Chubut; los «Aónikenk o Tehuelches Meridionales Australes» habitaban entre este último y el estrecho de Magallanes. Sin embargo y sobre todo después de volverse ecuestres (finales del siglo XVIII), sobrepasaron ampliamente los límites septentrional y occidental y entraron en territorios de otras agrupaciones «a través de rutas perfectamente determinadas (y quizá en cierto modo controladas)» (Casamiquela 1965: 74), con el objetivo principal de arribar a los centros de comercio en el norte de la Patagonia argentina ${ }^{1}$.

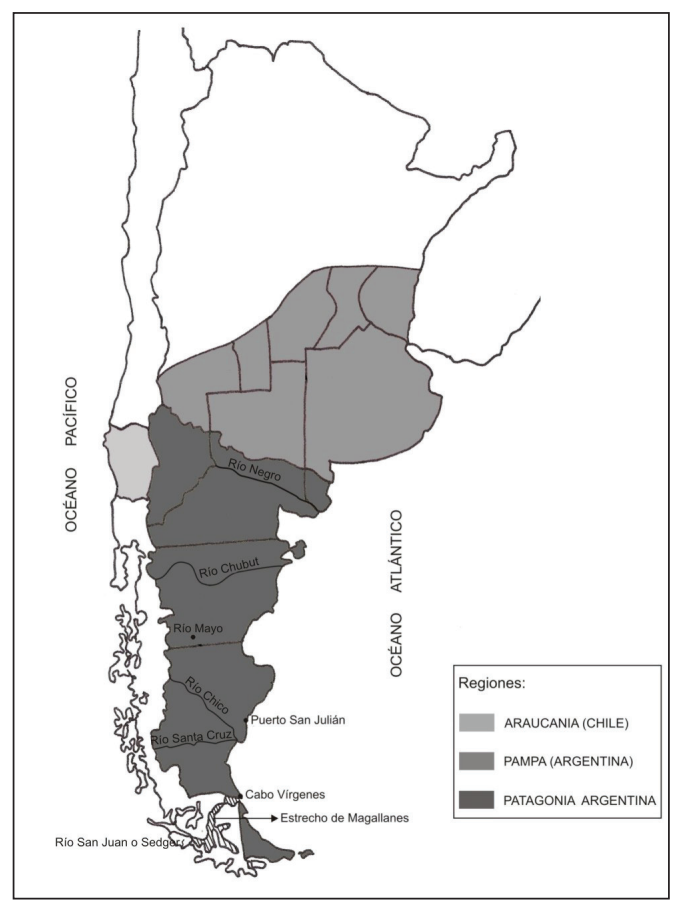

Figura 1: Ubicación de las regiones Araucanía, Pampa y Patagonia argentina.

\footnotetext{
1 Según este mismo autor, no sucedía lo mismo con sus vecinos del norte, los «gününa këna» o «tehuelches septentrionales», quienes durante ese mismo período, si bien sobrepasaron el límite del río Chubut y se adentraron en territorio aónik'enk con cierta frecuencia -y principalmente después de la adopción del caballo-, no lo hicieron de forma sistemática tal como parecen haberlo hecho los aónik'enk (Casamiquela 1965: 73).
} 


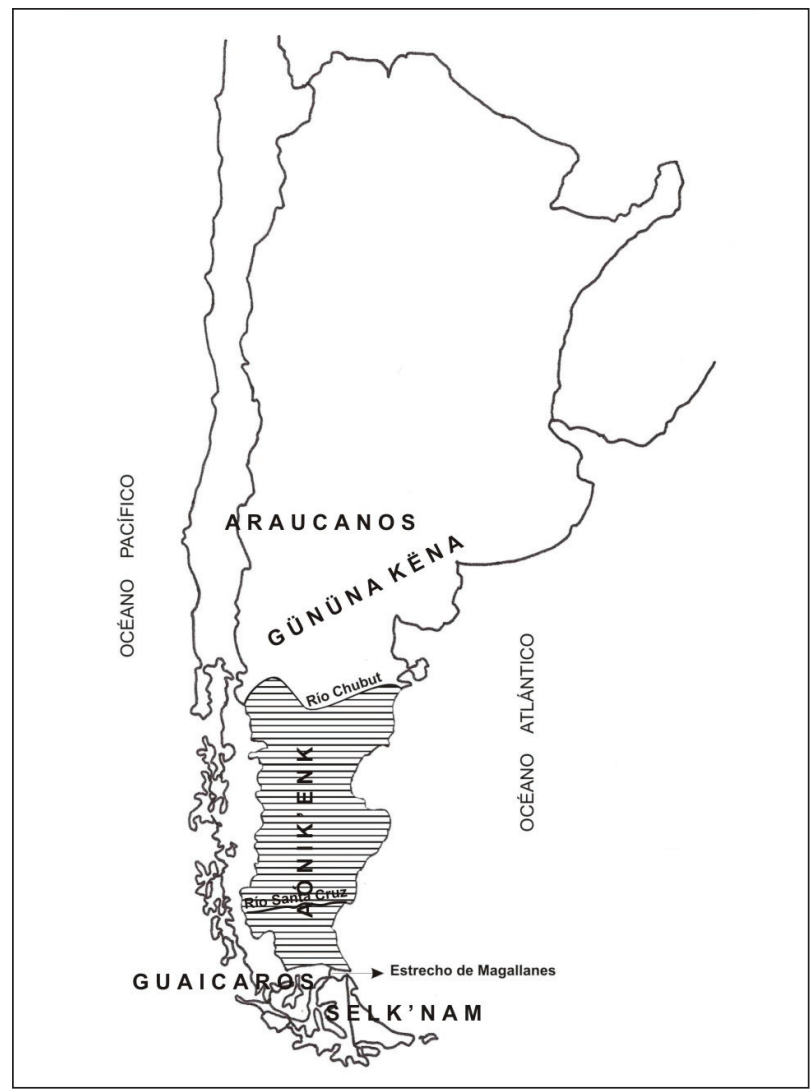

Figura 2: Ubicación de algunos grupos indígenas entre mediados del siglo XVII y finales del siglo XIX, según Casamiquela (1965).

Desde tiempos prehistóricos y hasta la década de $1880^{2}$, los aónik'enk -así como sus vecinos inmediatos del norte, los gününa këna- se especializaron en el trabajo de pieles y cueros, materiales que emplearon para la realización de numerosos elementos útiles para su forma de vida: desde sus moradas hasta su vestimenta, los elementos de su montura y numerosos utensilios domésticos. Asimismo desarrollaron otras prácticas entre las cuales se encuentra la textilería ${ }^{3}$.

Debido quizás a la relevancia que tuvo el trabajo de las pieles entre estas agrupaciones, han sido varios los estudios que han analizado con mayor o menor profundidad las particularidades de ese arte que aún perdura entre algunos pobladores de las zo-

2 En esta década (1879-1886) la Campaña de Conquista del Desierto produjo profundos cambios en las culturas de los grupos indígenas de la Patagonia. Esa Campaña consistió en operaciones militares llevadas a cabo por el gobierno de la República Argentina que tuvieron como principal objetivo expandir las fronteras nacionales a los territorios patagónicos hasta ese momento ocupados por los indígenas.

3 Se define como textil toda elaboración producida en forma manual y no seriada, realizada exclusivamente en telar y que se distingue del trenzado por la formación mecánica del cruce de los hilos de la urdimbre con los de la trama (Chertudi y Nardi 1961). 
nas rurales de esa región (Gómez Otero s/f; Irusta de Benbassat 1986; Caviglia 2003; Finkelstein 2008). Y quizás también por esa razón son escasos los trabajos que han indagado sobre las particularidades del arte textil que desarrollaron esas agrupaciones patagónicas. Varios han mencionado la posible procedencia de la tejeduría «tehuelche» y aónik'enk y han planteado algunas hipótesis sobre la forma en que habría sido adoptado este arte. Algunos lo han efectuado en el marco de estudios más amplios y, por eso mismo, sin profundización en la temática (Gómez Otero s/f; Palermo 1994; Martinic 1995) y otros, visualizando esta carencia, se han focalizado en su análisis (Méndez 2010).

Asimismo, algunos estudios han planteado hipótesis sobre las razones del desarrollo de la textilería entre los aónik'enk, en ciertos momentos históricos, y sobre el escaso desarrollo de esa práctica en otros períodos, pero sin brindar fundamento empírico. Esto se debe principalmente a que esas hipótesis se han formulado en el marco de estudios centrados en otras cuestiones (Millán de Palavecino 1963; Palermo 1991: 165; 1994: 65-66; 1999; Mandrini y Ortelli 2006). Y es precisamente esta carencia la que se pretende cubrir con el presente trabajo: brindar información empírica para determinar si tales hipótesis vigentes resultan satisfactorias y en caso de no ser así proponer nuevas hipótesis y/o un nuevo marco explicativo.

Se estima que esta indagación sobre las razones que habrían llevado a los distintos grupos humanos a adquirir saberes y prácticas foráneas resulta relevante, debido fundamentalmente a que permite profundizar sobre «la historia específica y única de cada grupo» (Boas 1964: 10). Esto implica superar las explicaciones que atribuyen las modificaciones culturales al simple contacto con parcialidades culturalmente diferentes. Como afirma Monk en su estudio preliminar al trabajo de Boas, «Probar que un trazo cultural ha sido prestado o incorporado es un esfuerzo descriptivo inconducente que no trasciende los efectos de la mera cronología. Lo significativo sería revelar por qué ciertos trazos han sido aceptados con mayor facilidad, por qué otros han sufrido resistencias y rechazo y por qué unos fueron incorporados con diferente sentido, con formas modificadas» (Boas 1964: 10).

Para lograr ese objetivo principal se propone, en primer lugar, el analizar brevemente los supuestos teóricos de las hipótesis vigentes sobre las razones de la adopción de la textilería por los aónik'enk. Para ello se brinda y analiza información empírica al respecto y se evalúan esos supuestos a la luz de esta información; y en segundo término, el plantear un marco teórico alternativo y revisar un planteamiento que hemos formulado en otro trabajo. Para ello se ofrece y analiza información sobre algunas características de los textiles que los aónik'enk elaboraron y los usos que les dieron. La información que utilizamos proviene de fuentes primarias consistentes en documentos escritos e ilustraciones editadas, de fuentes secundarias que comprenden resultados de estudios históricos, etnográficos y arqueológicos publicados, y resultados inéditos de trabajos etnográficos desarrollados en la actual provincia de Chubut (Patagonia argentina).

\section{Hipótesis vigentes sobre la adopción de la textilería por los aónik’enk}

Millán de Palavecino ha argumentado que la adopción del tejido por los tehuelches habría respondido a la dificultad que comenzaron a tener para conseguir pieles a partir del 
establecimiento de las primeras estancias en esa región (1963). Ese establecimiento fue posterior a la finalización de la Campaña de Conquista del Desierto por lo que, según esta autora, la adopción de la textilería por los tehuelches se remonta, como máximo, a finales del siglo XIX.

Otros autores han asegurado que la existencia de ganado ovino fue determinante para el desarrollo de la textilería entre las agrupaciones indígenas de Pampa y Patagonia: Palermo ha planteado una relación directa entre la expansión del ganado ovino y la tejeduría indígena (Palermo 1991: 165; 1994: 65-66; 1999); Mandrini y Ortelli han sostenido que el ganado ovino fue «un recurso esencial» en la provisión de lana para las tejedoras indias (Mandrini y Ortelli 2006: 29). Según estas afirmaciones y a partir de la información existente acerca de la posesión y posibilidad de acceso a las ovejas por aquellas agrupaciones (Martinic 1995; Onelli 1977), la tejeduría se habría desarrollado entre los aónik'enk después de finales del siglo XIX.

En primer lugar, ambas conjeturas sostienen implícitamente la existencia de una lógica material subyacente a la práctica textil y al empleo de las pieles por los indígenas. Ambas dan prioridad «a las condiciones tecnoecológicas y tecnoeconómicas en que se encuentra la población humana» y «centran su atención en la interacción entre la conducta y el entorno físico establecida a través del organismo humano y de su aparato cultural» (Harris 1996: 489, 571).

En segundo término, estas hipótesis suponen una situación de escasez que habría alentado o impedido el desarrollo de la práctica textil entre los indígenas de Pampa y Patagonia: en la primera, la escasez de pieles habría conducido a la adopción de la textilería por los tehuelches; en la segunda, la posesión de ovejas habría sido fundamental para el desarrollo de la textilería entre los indígenas de las regiones Pampeana y Patagónica o, lo que es lógicamente lo mismo, la carencia de ovejas habría impedido el desarrollo de la textilería entre esos grupos.

En síntesis, las hipótesis referidas sostienen que, a rasgos generales, la adopción de la textilería por los tehuelches y por las agrupaciones indígenas de Pampa y Patagonia, estuvo supeditada al entorno material y a una situación de escasez: la escasez de algunos medios habría determinado el desarrollo de la textilería y la escasez de otros habría conducido a la ausencia de desarrollo de la misma. Sin embargo ninguna de esas hipótesis ha sido corroborada con información empírica. A continuación nos abocamos a ello.

\section{Análisis de la información empírica sobre la presencia de la práctica textil entre los aónik'enk ${ }^{4}$}

La referencia más antigua que encontramos sobre la realización de tejidos por los aónik'enk data de 1783 y corresponde al cronista y colonizador Antonio de Viedma. Sostiene que los indígenas de las proximidades de San Julián «se ciñen la cabeza con

\footnotetext{
4 Las primeras fuentes primarias sobre la Patagonia datan del siglo XVI. Entre este siglo y el XVIII son escasos los procesos judiciales y las cobranzas, y las principales fuentes escritas de información son las crónicas de navegantes y misioneros. Desde finales de ese siglo los documentos son más numerosos y minuciosos y comprenden principalmente informes de funcionarios y científicos.
} 
una cinta de lana como de dos dedos de ancho, tejida por ellos de varios colores» (Viedma 1837: 69).

El siguiente testimonio encontrado fue elaborado cincuenta años más tarde, entre finales de 1833 y comienzos de 1834, y corresponde a los misioneros anglicanos Coan y Arms, quienes informan sobre la existencia de una práctica textil entre algunos indígenas que habitaban el territorio próximo al estrecho de Magallanes. Relata Coan: «Salimos para ver entre ellos el proceso de tejido. Vimos en el telar una tela destinada a ser una colcha y a la tejedora dedicada a su trabajo [...] El hilo con el que se hacen estas colchas es devanado de la lana de guanaco. Su fibra es larga y suave. Se lo extrae con los dedos y es retorcido por medio de una caña sostenida en una mano. Se lo colorea con varios tipos de arena, que se consiguen en el interior del país (Coan 2006 [1880]: 122-123). También su compañero de viaje, Arms, asegura en su diario que las mujeres indígenas cosen en un proceso muy tedioso, tejen de manera igualmente laboriosa» (Coan 2006: 199).

El siguiente documento hallado corresponde a la década de 1860 y fue elaborado por el capitán de Guardias Nacionales argentino Doroteo Mendoza, quien relata que las mujeres indígenas pertenecientes a la agrupación liderada por Casimiro y parcialidades aledañas a la zona del río Santa Cruz «por lo regular, son laboriosas; se ocupan de hacer tejidos, mantas, fajas y cintas de lana, hilo y seda bastante finos y de labores curiosas; pero, como carecen de lana, se valen de deshilar las bayetas y de la filana a la rueca y el huso, tuercen el hilo de varios colores, más o menos fino, según lo precisan (Mendoza 1965: 67-68). Tal como sostiene Vignati en las notas consignadas en el escrito de Mendoza, probablemente existan algunos errores en estas aseveraciones del autor: primeramente, resulta sumamente extraño que se empleen hilos de seda para tejer en esa región; en segundo lugar, el término «filana» es desconocido en la lengua española.

Los autores citados ofrecen también algunos datos sobre las particularidades técnicas del hilado y del tejido. Como expusimos en otros trabajos (Méndez 2009a; 2009b; 2010), los métodos descritos son los mismos que los empleados en la actualidad y desde hace siglos por las tejedoras de la Araucanía y difundido en las regiones Pampeana y norte de la Patagonia. El telar representado por Coan corresponde al de uso más extendido en esas regiones, y que ha sido denominado telar vertical o «telar mapuche» por numerosos estudiosos de la textilería americana (Méndez 2009a). En cuanto a la referencia de Mendoza, es demasiado vaga como para llegar a alguna identificación definitiva, aunque es posible suponer que corresponde a la misma tradición textil.

La cuarta alusión al arte textil entre los aónik'enk corresponde a Musters, quien convivió con algunos de ellos entre 1869 y 1870 . Este autor refiere que las mujeres aónik'enk tejían «de la misma manera que el marinero fabrica un pallete de los llamados 'de sable'» (Musters 2005 [1911]: 204). Según el Diccionario Marítimo Español publicado en 1864, se denomina «pallete á sable» a un tejido de meollar o de cordones de cabo «que se teje pasando un cabito llamado madre por entre varios cordones paralelos, y azocándolo a golpes con una pieza de madera semejante a la hoja de un sable» (Lorenzo, et al. 1864). Esta técnica mencionada por Musters puede corresponder al mismo telar referido por Coan o al denominado «telar vertical de faja pampa» 
(Chertudi y Nardi 1961) o «de palillos o de cañas» (Millán de Palavecino 1932; 1963) también empleado en Araucanía y difundido en la Pampa y norte de la Patagonia.

Si se consideran estos relatos como verídicos, hacia la octava década del siglo XVIII algunas agrupaciones aónik'enk realizaban tejidos y su técnica era probablemente deudora de la tradición textil proveniente de la Araucanía. Esto último resulta plausible si se considera que ellos mantuvieron relaciones con los indígenas pampeanos y norpatagónicos desde los primeros tiempos históricos e incluso prehistóricos (Casamiquela 1965; Hadjuk 1981-82), quienes a su vez estuvieron en contacto con las parcialidades araucanas realizadoras de tejidos (Palermo 1991; 1994). Estas relaciones se intensificaron con la incorporación del caballo por los indígenas patagónicos, lo cual permitió, entre otras cosas, el incremento y la velocidad de los desplazamientos. Específicamente en el caso de los aónik'enk, la etapa ecuestre se inicia entre finales del siglo XVII y comienzos del XVIII, lo cual hizo posible que estas parcialidades mantuvieran contactos directos con los araucanos ${ }^{5}$ y grupos araucanizados a ambos lados de la cordillera (Cox 1999 [1863]: 239) ${ }^{6}$.

Estos testimonios sobre la existencia de una práctica textil de las características descritas entre los aónik'enk, resultan sorprendentes si se tiene en cuenta que hacia la época analizada dichos grupos eran cazadores-recolectores con una alta movilidad que dependía, la mayoría de las veces, de la posibilidad de obtener su principal fuente de sustento: el guanaco. La alta movilidad de estos grupos aborígenes y el tiempo que requería -y requiere- la confección de esos tejidos habría condicionado grandemente la tarea: el traslado de los telares con las confecciones inconclusas requeriría de una gran destreza para no echar todo el trabajo a perder: habría que evitar el cruce de los hilos de la urdimbre y del lizo, mantener la tensión del tejido inconcluso, etc.

Por otra parte, la geografía del país aónik'enk carece de árboles de donde obtener los palos rectos y fuertes necesarios para la confección del telar empleado, ya que dichos palos deben ser capaces de soportar la presión que se ejerce sobre el hilo de la trama y la tensión de los hilos de la urdimbre. Como se expuso en otro trabajo y a través del análisis de ciertos documentos escritos y gráficos, este inconveniente probablemente se soslayó por el acceso a lugares fuera de sus territorios en donde también obtenían los palos para los toldos y para otras necesidades (Méndez 2010). Resultaba un hecho usual -y hoy en día en algunas regiones de la Patagonia lo continúa siendo- el recorrido de grandes distancias para la búsqueda y selección de los palos adecuados para ser empleados en los telares. En algunas familias tal esfuerzo encuentra su justificación en que los mismos (junto con los demás utensilios) son transmitidos a las sucesivas generaciones de mujeres (Méndez 2009a).

\footnotetext{
5 Según algunos autores, «araucano» es un gentilicio formado en castellano a partir de la castellanización del mapuche «ragko», que los conquistadores españoles emplearon para denominar a los pobladores de la región de la cuenca inferior del río Biobío (Chile); según otros estudiosos, deriva de la voz quechua «auca» con la cual los Incas identificaban a los indígenas que habitaban al sur del río Maipo (Chile). En este trabajo, como en gran parte de la bibliografía científica, se emplea como un hiperónimo por razones prácticas, puesto que permite englobar a las parcialidades que en las fuentes primarias analizadas han sido identificadas como «mapuches», «pehuenches», «huilliches», «picunches», «moluches», entre otras.

6 Cabe aclarar que la adopción del caballo por los distintos grupos aónik’enk no se realizó en un mismo momento, encontrándose testimonios de su existencia en algunas zonas hacia comienzos del siglo XVII, e indicios de pedestrismo en algunas parcialidades hasta comienzos del siglo XVIII (Martinic 1995: 75, 76).
} 
Paralelamente a los testimonios citados que mencionan la práctica textil entre los aónik'enk, existen otros que permiten vislumbrar un panorama diferente dentro de las diferentes parcialidades englobadas bajo esta denominación. Como ejemplo, Jorge Barne registró a mediados del siglo XVIII que los navegantes del bergantín San Martín estuvieron en contacto con varios indígenas a la altura del puerto San Julián. Según el testimonio de éstos, los nativos les ofrecieron «muchas de aquellas pieles, piedras bezares, lana de huanaco, aunque algunos dicen que era de vicuña; pero como todo naufragó no se ha podido averiguar la realidad y distinción de dicha lana» (Barne 1837: 17). Este documento informa que, además de las pieles, los indígenas ofrecieron lana de camélido a los navegantes. Pero también abre nuevas cuestiones: ¿esta lana fue obtenida de los camélidos por ellos mismos o fue adquirida? ¿Era empleada sólo para comerciar y obtener, entre otras cosas, los ponchos que vestían tales nativos o también era empleada para realizar dichas prendas?

Un siglo más tarde, Musters asegura que los indígenas de la región meridional de la Patagonia, con quienes estuvo en contacto, no aprovechaban la lana del guanaco, sino que tejían «las vinchas para la cabeza [...] con hilo de telas deshiladas obtenidas por trueque en las colonias, o de sus vecinos araucanos» (2005 [1911]: 204). Según este viajero: «Es indudable que la lana [de guanaco] podría ser aprovechada con fines mercantiles, porque su contextura es muy delicada y actualmente tiene valor en Chile, donde se la teje para hacer ponchos que se venden a altos precios» (Musters 2005: 153).

En una carta fechada en 1865 del cacique Antonio (líder de un grupo integrado por tehuelches septentrionales y meridionales) al Señor Jones, Superintendente de la Colonia del Chupat, le informa de que: «Vendemos también pieles de guanaco y, si ustedes desean llevaremos además lana de guanaco; pero nuestro trabajo es hacer mantos de guanaco ('quillangos' ${ }^{7}$ ). Nuestras mujeres los hacen» (Claraz 2008: 178). Nada menciona acerca de la confección de tejidos, así como tampoco lo hacen Moreno, Lista y Schmid -entre otros que convivieron con algunos aónik'enk en el siglo XIX- quienes tampoco hacen referencia al comercio de la lana de guanaco.

De lo expuesto hasta aquí es posible deducir que:

1. Durante el siglo comprendido entre 1780 y 1880 algunos grupos aónik'enk realizaron textiles con el pelo de los guanacos, otros los hicieron con hilos de telas, otros comercializaron el pelo de guanaco y otros no efectuaron ninguna de las dos actividades, no siendo excluyente, probablemente, la combinación de algunas de estas tareas dentro de un mismo grupo. Esto implica que la textilería era practicada por algunos grupos aónik'enk un siglo antes de lo supuesto hasta el momento.

2. La actividad textil presente entre algunos aónik'enk, parece derivar del contacto con las agrupaciones del norte de la Patagonia y de la Araucanía, es decir, ese contacto parece ser la condición necesaria -no el fundamento- de la adopción de la textilería por algunos aónik'enk.

3. Las primeras referencias halladas sobre la elaboración de textiles corresponden a menos de una centuria después del desarrollo de la actividad ecuestre por los aónik'enk

7 Los quillangos son capas o mantos de pieles, normalmente confeccionados con cueros de guanacos nonatos y/o neonatos cosidos entre sí. 
y al mismo momento en que «disponían para su uso de gran cantidad de equinos» (Martinic 1995: 77). Sin embargo, no puede determinarse si ambas actividades se desplegaron en un mismo momento en un mismo grupo, aunque sí puede establecerse que algunas parcialidades adoptaron la actividad ecuestre pero no la tejeduría durante el período analizado.

4. Las primeras referencias sobre la práctica textil de los aónik’enk coincide con el establecimiento de las primeras colonias españolas en las costas patagónicas.

5. Algunos aónik'enk desarrollaron la textilería a pesar de habitar un medio que no ofrecía algunos recursos para la construcción de los telares y de llevar una vida nómade con una alta movilidad.

6. Algunas agrupaciones aónik'enk incorporaron la textilería en momentos que contaban con importantes provisiones de cueros de guanacos y, en menor medida, de caballos y vacunos (Martinic 1995: 112-113). Esto implica que, si bien la carencia de cueros puede haber sido la razón principal de la incorporación de la textilería por el grupo analizado por Millán de Palavecino, tal razón no debe hacerse extensiva a todas las agrupaciones comúnmente denominadas «tehuelches».

7. La inexistencia del ganado ovino entre los aónik'enk hasta finales del siglo XIX no fue un limitante para el desarrollo de la textilería. Como se ha mencionado, los hilos obtenidos del deshilado de algunas telas (como por ejemplo la bayeta) y el pelo de guanaco eran empleados en la confección de los tejidos. Si bien el primero resultaba una innovación posible gracias al contacto con las manufacturas europeas, el empleo del pelo de guanaco por los aborígenes de la región de la Araucanía se remonta a fechas anteriores a la conquista española de América del Sur (Méndez 2009a). Dicha práctica continuó vigente entre las agrupaciones al este de la cordillera y norte de la Patagonia a lo largo de los siglos XIX y XX (entre otros: Kermes 1893; Millán de Palavecino 1963) llegando incluso hasta la actualidad (Méndez 2009a). La principal fuente del sustento de los aónik'enk, los guanacos, podía brindar la materia prima para sus tejidos.

Hasta aquí la información referida permite relativizar las hipótesis vigentes. Sin embargo no alcanza a explicar las razones por las cuales algunos aónik'enk adoptaron la textilería. Para ello se propone analizar la forma que adquirió la textilería entre los aónik'enk, específicamente, qué tejidos realizaron y qué usos les dieron, los cuales son sólo algunos de los varios campos posibles de análisis para indagar sobre esos fundamentos.

\section{Los tejidos que realizaron y los usos que les dieron}

Como ya se ha mencionado, el primer testimonio hallado sobre los tejidos que confeccionaron los aónik'enk data de finales del siglo XVIII y corresponde a Antonio de Viedma. Este autor relata que los aónik'enk tejían cintas de lana que empleaban para sujetarse «el pelo doblado por arriba, con las puntas al aire como plumaje por el lado izquierdo, dándose con la cinta seis o ocho vueltas, y colgando las puntas de ella con unos cabetes de metal amarillo o latón [...] [las mujeres] Llevan descubierta la cabeza, dividido el pelo en dos partes, y de cada una hecha una coleta, que baja por las orejas y hombros hasta el pecho y cintura; cuya cinta es de lana parda de dos dedos 
de ancha, guarnecida, si es mujer rica, en días de gala con abalorios, y lo mismo las mujeres de alguna autoridad» (Viedma 1837: 69). Y a continuación informa que esas cintas o fajas tejidas por las mujeres aónik'enk y que usaban en su cabello también las empleaban en sus monturas: "Ponen a la yegua un collar al cuello que cae hasta las rodillas, con cuantos cascabeles y colgajos pueden conseguir. Estos arreos son para gala y fiestas, pero en sus marchas ordinarias no usan estos adornos, y en lugar de dicho collar ponen un cordón de lana azul o colorado, de un dedo de grueso, con el cual dan tres vueltas al cuello de la caballería, y los sirve también de estribo para montar en el sillón» (Viedma 1837: 71).

En cuanto a la referencia de Coan, en la traducción de su obra a la que se ha tenido acceso y en su descripción sobre el proceso de tejido de los aónik'enk, relata que lo que se está tejiendo es una «colcha» (Coan 2006 [1880]: 122); en la traducción ofrecida por Martinic, en cambio, se denomina a ese tejido «jerga» y se agrega: «la operación [de tejido] es muy lenta requiriéndose cerca de dos semanas para concluir una de estas jergas: por consiguiente son muy escasas y nunca he visto media docena de ellas reunidas. Las que se hallan, se usan por lo general para enjaezar los caballos de los grandes» (Martinic 1995: 259). Lamentablemente no se ha podido acceder al texto en su idioma original para determinar si el autor hace referencia a una colcha o una jerga. Sin embargo, sabemos que en la Patagonia y en la región Pampeana, las jergas (comúnmente denominadas matras) han sido empleadas como mantas o colchas, y viceversa (Coan 2006 [1880]: 79; Cox 1999 [1863]: 175; Musters 2005 [1911]: 91, entre otros). Tal como asegura Fiadone «El uso habitual de la matra como cobija o colchón $[\ldots]$ habrá hecho que a veces se confundieran los términos, y se usaron indistintamente para hacer referencia a la prenda y su uso ecuestre o a su adaptación doméstica» (Fiadone 2007: 77). Por otra parte, la medida que según Coan tenía el tejido era 1,30 m de longitud, lo que coincide con el tamaño que generalmente tenían estas piezas (Chertudi y Nardi 1961: 159; Marí y Taranto 2001: 92). Paralelamente, su compañero de viaje Arms asegura que las mujeres aónik'enk «hacen cobertores con lana de guanaco que han coloreado a toda prueba y que sus maridos usan bajo sus monturas» (Coan 2006 [1880]: 199), una afirmación que parece confirmar las especulaciones sobre la descripción de Coan.

Años más tarde, Mendoza y Musters refieren que las mujeres aónik’enk hacían mantas, fajas, cintas y ligas para las botas de montar (Mendoza 1965: 63; Musters 2005 [1911]: 86, 194). Según este último autor, las fajas realizadas por las aónik’enk eran empleadas en su vestimenta para sostener su manta de guanaco y también en el apero para ajustar la montura de las mujeres (Musters 2005: 96 y fig. p. 95).

A través de un trabajo arqueológico en el alero Mazquiarán, en las proximidades de Río Mayo, frente al río Guenguel, se halló un enterramiento con una estructura que permite asociarlo a un grupo «tehuelche» y que correspondería a finales del siglo XVIII y comienzos del XIX. En él se encontraron fragmentos de una faja, un poncho y un chamal junto a varios cueros pintados. La técnica de confección de la faja, sus 
dimensiones y su diseño resultan idénticos a una faja tejida por los aónik'enk que presenta Martinic (1995: 212), lo que permite especular que sería de su confección ${ }^{8}$.

No se han hallado otras referencias sobre los tejidos que realizaban los aónik'enk antes de la década de 1880, lo cual resulta sorprendente teniendo en cuenta la numerosa documentación analizada. Pero aunque esta información resulta escasa permite plantear algunas conjeturas:

1. Los aónik'enk tejieron prendas que tuvieron más de una finalidad.

2. Esas finalidades comprenden las relacionadas con la actividad ecuestre, con la actividad doméstica y con el adorno corporal, pero no se extiende a la vestimenta. No se han encontrado testimonios sobre la confección de tejidos para vestir a pesar de que existen abundantes referencias relativas a la vestimenta de los aónik'enk desde el momento de los primeros testimonios sobre su elaboración de tejidos, es decir, desde finales del siglo XVIII.

Consideramos relevante centrarnos por un momento en este último aspecto, es decir, la vestimenta de los aónik'enk, para poder realizar algunas inferencias respecto a las razones por las cuales algunos de ellos adoptaron la textilería.

Hacia el momento de los primeros testimonios sobre la práctica textil entre los aónik'enk, el Capitán de Navío Antonio de Córdoba se encontró en reiteradas oportunidades con indígenas a caballo en las proximidades del cabo Vírgenes. «Uno hablaba muy poco el Español, de lo que se infirió había tenido bastante comunicación con nuestros establecimientos de la Costa Patagónica, pues nombraba algunas veces al Capitán Antonio Viedma, y al Piloto Bernardo Tafor: traía un Poncho de pañete de los que se fabrican en la Provincia del Río de la Plata, y su trage era el mismo que usan los criollos de la América Meridional, con sólo la adición de una especie de manta de pieles de Guanaco, cosidas entre sí, y en todo idénticas á las que venden los Indios en los establecimientos de la citada Provincia» (Córdoba 1788: 20-21). Más adelante agrega que, en esa misma zona, los aborígenes vestían «una manta de pieles de guanacos ó de zorrillos medianamente compuestas con rayas de diferentes colores en la parte interior [...] Algunos traen unos ponchos y calzones de igual género y hechura que los Criollos del Reyno de Chile y Buenos Ayres, no excluyendo este trage la manta de pieles. El poncho se reduce á una pieza de texido fuerte, rayado de diferentes colores de tres varas de largo sobre dos de ancho con una abertura en su mitad proporcionada para entrar la cabeza francamente [...] Algunos tenian ponchos de pañete de los de nuestras Fábricas de la Provincia de Buenos Ayres [...] Pocos eran los que disfrutaban de estas comodidades: lo mas estaban desnudos y reducidos á sus mantas de pieles y á una bolsa de cuero, que colgando de una correa que llevaban ceñida á la cintura les cubria sus partes vergonzosas» (Córdoba 1788: 330-331).

Estas descripciones coinciden con las observaciones realizadas por Viedma hacia la misma época quien informa que, entre los indios cercanos a San Julián, solamente

8 En base a su similar diseño con una faja «sarachumpi», Pérez de Micou (2009) sostiene que probablemente la faja hallada provenga del noroeste argentino (NOA). Si bien no descartamos esta posibilidad, sus particularidades permiten asignarle una procedencia aónik'enk. 
las prendas de cuero utilizadas debajo de dicha manta (de pieles) fueron siendo alternativamente reemplazadas por tejidos araucanos o telas industriales (Viedma 1837: 70).

En el año 1827, en su viaje al estrecho de Magallanes, Fitz Roy relata que la vestimenta de los hombres y mujeres que se hallaban en las proximidades del Estrecho eran de pieles de guanaco. Al mismo tiempo describe la montura de uno de los hijos de la «cacica» María: «One of the young men, whom we afterwards found to be a son of Maria, who was a principal person of the tribe, was mounted upon a very fine horse, well groomed, and equipped with a bridle and saddle that World have done credit to a respectable horseman of Buenos Ayres or Monte Video. The young man wore heavy brass spurs, like those of the Gauchos of Buenos Ayres» (Fitz Roy 1839: 18). Y más adelante relata la manera en la que María se presentó a ella misma: «and stated herself to be sister of Bysante, the cacique of a tribe near the Santa Cruz River, who is an important personage, on account of his size (Vich Maria described to be immense), and his riches. In speaking of him, she said he was very rich; he had many mantles, and also many hides ('muy rico, tiene muchas mantas y tambien muchos cueros')» (Fitz Roy 1839: 86).

Se evidencia en estos relatos la importancia que tenía para los aónik'enk la posesión de una buena montura, de mantos (de pieles de guanaco) y de cueros como símbolo de poder y estatus. Tales parcialidades estaban en contacto, en forma directa o indirecta, con los centros comerciales criollos en donde tenían la posibilidad de adquirir esas monturas y también telas y textiles. Sin embargo, esto último no parece haber sido un elemento que otorgara prestigio a su portador, por lo menos en el momento y lugar al que hacemos referencia.

Menos de diez años después encontramos en estas mismas agrupaciones próximas al Estrecho la actividad textil descrita por Coan y Arms, en donde -vale recordarlo- se confeccionaban y empleaban tejidos para las monturas que a la vez se usaban como colchas o mantas, pero sin mencionar su uso en el vestido. Según estos autores, la vestimenta de los hombres y las mujeres con los cuales convivieron consistía exclusivamente de cueros (Coan 2006 [1880]: 60, 61, 79, 85, 197).

Schmid, quien estuvo en contacto con los aborígenes que habitaban la región comprendida entre el estrecho de Magallanes y el río Santa Cruz entre los años 1858 y 1861, comenta que su «vestimenta más común, a la vez que la más primitiva, consiste en una capa hecha con pieles de guanacos jóvenes, blandas y suaves, con la que se cubren del cuello a los tobillos. También usan pieles de zorrinos, aunque esto es menos común [...] No faltan tampoco las de piel de liebre [...] Hombres y mujeres visten igual, pues la capa es la misma; la diferencia radica en el modo de usarla» (Schmid 1964: 171-172).

Hacia la década de 1860, Musters afirma que entre los aónik'enk «la manta de piel amplia y abrigada suple a todas las demás ropas» (Musters 2005 [1911]: 193), y si bien sostiene que «El traje de los hombres consiste en un chiripá, con este término el autor no se refiere exclusivamente a una prenda tejida, sino que puede estar confeccionada por un poncho, o de un pedazo de tela, y también de piel de guanaco» (Musters 2005 [1911]: 193).

En su Viaje al río Chubut, realizado entre los años 1865 y 1866, Claraz informa que los indígenas de su partida (tehuelches meridionales y septentrionales) usaban 
siempre quillangos y que, ante un frío muy intenso, se colocaban un poncho encima de éste (Claraz 2008: 98, 106, 133, 135, 151). Además realiza un comentario interesante al respecto: «El carácter femenino se manifiesta en la constancia con que continúan la misma rutina, sin cambiar nada. En las mujeres esto es más fuerte que en los hombres. Se percibe en ello cierta gradación. El chileno, por ejemplo, ya se viste en forma parecida al gaucho, mientras que el pampa conserva su quillango. Más rutinario es aún el tehuelche. Y peor todavía son los fueguinos» (Claraz 2008: 87).

En 1879, Moreno relata que los hombres y las mujeres aónik'enk que se hallaban en las proximidades del río Santa Cruz, vestían quillangos (Moreno 1969 [1879]: 340). Hacia la misma época, Lista describe la vestimenta de los hombres y mujeres de las cercanías del río Chico de la siguiente manera: «El traje de los hombres se compone de chiripá de algodón o de paño; una capa de pieles de guanaco, y en ocasiones camisa y calzoncillos que compran en Punta Arenas o en Carmen de Patagones. Usan también tiradores con adornos de plata, vincha y botas de cuero de potro [...] Las mujeres visten comúnmente una especie de camisa de zarza o de lienzo, sin mangas, que las cubre de los hombros al tobillo, y sobre la cual llevan en toda estación la indispensable capa de pieles o de tela de lana» (Lista 1975 [1881]:115, 117).

Hacia 1887, Castillo relata que en las proximidades del río Chico «El vestuario de los hombres y de las mujeres está constituido por una capa de pieles que los cubre de cuello a pie, usando unos y otros camisas de tela» (Castillo 1979: 41).

Estos testimonios permiten afirmar que, desde finales del siglo XVIII hasta la década de 1880, los aónik'enk emplearon como vestido principal el manto de cuero, el cual eventualmente se acompañaba por prendas de telas industriales o por tejidos aborígenes que ellos no confeccionaban y que adquirían a través de los intercambios con otras agrupaciones indígenas y con las colonias, una práctica que parece extenderse hasta bien entrado el siglo XX (Coan 2006 [1886]: 185; Musters 2005 [1911]: 91, 136; Viedma 1938: 591, entre otros) ${ }^{9}$.

Se ha hallado un testimonio que puede considerarse una excepción al respecto, que data del año 1752 y corresponde al Capitán Barne. Este autor asegura que recibió información acerca de un cacique y algunos acompañantes que se encontraban a la altura de San Julián, quienes «vestían ponchos y los cuidaban mucho» (Barne 1837: 17). Consideramos que este último dato debe ser considerado a la luz de las descripciones antedichas, lo cual nos deja ver que el empleo de los tejidos como principal vestido hasta fines del siglo XVIII parece ser más una excepción que una regla para los aónik'enk. Por otra parte, estimamos que debe tenerse en cuenta que hacia esa época también se denominaba poncho a las prendas realizadas con pieles y que se portaban de la misma manera que aquéllos (Marí y Taranto 2001: 12).

\footnotetext{
9 Si bien en el período inmediatamente posterior a esta década se generalizó el empleo de vestimentas foráneas obtenidas en los centros de intercambio, el quillango continuó siendo la prenda distinguible de los aónik'enk (Martinic 1995: 144-145). En los últimos tres años del siglo XIX, Hatcher informa que el quillango era la principal vestimenta de los indígenas que habitaban entre el río Santa Cruz y el estrecho de Magallanes (Hatcher 2003: 23). Incluso, en la primera década del siglo XX, Onelli afirma que «La raza tehuelche, que más o menos ha vivido siempre entremezclada con la araucana, debe haber aprendido de ésta el arte del telar. Y más adelante agrega: el indio tehuelche jamás usa poncho: su abrigo favorito es el quillango de guanaco [...]» (Onelli 1916: 47).
} 
Esta continuidad en el empleo de los mantos de pieles como principal vestido a pesar de la incorporación de la textilería por algunos aónik'enk, puede haber tenido una razón práctica. Según Musters, los mantos de guanaco eran fáciles de secar después de una lluvia, aunque siempre se debía tener cuidado de secarlas del lado del pelo para evitar resquebrajar el cuero (Musters 2005 [1911]: 122). Otro beneficio del empleo de los mantos de cuero puede haber sido la posibilidad de proteger la boca del portador con su pelo en los días de viento muy frío para evitar el dolor de encías, como también informa este autor (Musters 2005: 194).

Para Claraz, los mantos confeccionados con pieles de guanacos jóvenes eran los más aislantes: «Los animales que habitan en climas fríos tienen por naturaleza una protección apropiada. Entre los guanacos jóvenes, los intersticios entre los pelos están llenos de duvet, que por su constitución molecular y su contextura mecánica es uno de los peores conductores» (Claraz 2008: 203).

Asimismo, los quillangos parecen haber tenido la facultad de identificar la procedencia de las personas en la distancia, lo cual más de una vez pudo haber evitado un infortunio. La experiencia relatada por Casimiro ilustra esta idea: «Éste [Casimiro], al ver que se acercaban cinco indios montados, envueltos en sus ponchos, en la incertidumbre de si eran araucanos o tehuelches sacó el revólver, preparándose para despacharlos uno por uno; pero en seguida, con gran satisfacción, reconoció en el guía a un pariente suyo» (Musters 2005 [1911]: 133).

Cierta información que proporciona Cox puede ayudar a respaldar esta idea de la importancia del uso de los mantos de cuero como forma de identificación. Este autor relata que en las tolderías «cosmopolitas» de los «pehuenches», en donde convivían aónik'enk, gününa këna, «guaicurúes» (guaicaros) y «cristianos», las mujeres realizaban las tareas propias de cada grupo: tejían «a la usanza araucana» y también «preparaban cueros de guanaco» según las técnicas «tehuelches» (Cox 1999 [1863]: 222). Al mismo tiempo, mantenían las costumbres propias de cada grupo en la vestimenta; las mujeres «pehuenches» vestían en forma similar a las «araucanas» mientras las mujeres «tehuelches» que vivían entre los «pehuenches», a pesar de tener a su disposición prendas tejidas, «sólo [usaban] cueros de guanaco como vestido, pero con los mismos adornos de las otras» (Cox 1999: 223).

También es posible que el mantenimiento de los quillangos como principal vestimenta haya tenido una razón simbólica si tenemos en cuenta los significados que tenían estos mantos entre los «tehuelches» (Casamiquela et.al. 1991; Caviglia 2003, entre otros). Los quillangos identificaban a sus portadores: los dibujos plasmados en ellos indicaban su estatus, algunas de sus vivencias y el grupo de pertenencia. Los mantos de pieles formaban parte de sus mitos de creación y de los ritos de paso durante la vida de cada «tehuelche», desde su infancia hasta su muerte. Dice Caviglia al respecto: «[...] comenzamos a comprender con más profundidad que las capas pintadas son mucho más que un simple abrigo o una vestimenta pintada [...] vemos cómo se condensan estos esquemas cosmovisionales profundos [...] Estas capas que son todas diferentes, pues están hechas para cada persona, cada familia, cada grupo, generan simultáneamente vínculos de pertenencia e identidad» (Caviglia 2003: 56).

A partir de lo mencionado, resulta dudosa la aseveración de Vignati, según la cual, para las agrupaciones indígenas de la Patagonia meridional, «Las prendas tejidas 
a mano, eran de mayor valor que los mantos de piel» (cita número 50 en Mendoza 1965: 34). Ello puede resultar acertado si interpretamos la valía de algunas de estas prendas como el valor monetario o de cambio; pero si consideramos la valía como el valor simbólico o de uso, ello resulta erróneo para el caso de los aónik'enk. Si bien los hombres araucanos empleaban los ponchos (tejidos) como principal prenda de vestir y abrigo y su uso estaba extendido entre los gününa këna, los documentos antes citados dan cuenta de que no sucedía lo mismo con sus vecinos meridionales.

Pero si bien los quillangos se mantuvieron como su vestido principal a lo largo del período analizado, los aónik'enk usaron ampliamente los textiles en la montura y al mismo tiempo como mantas y cojines (Musters 2005 [1911]: 91), como tapete para jugar a las cartas (Musters 2005: 208), para construir «la casa bonita» en donde se celebraban algunos ritos como los de nacimiento y entrada en la pubertad (González 1965: 23, 29; Lista 1975 [1881] 117-118; Musters 2005: 100, 210, 224; ), para envolver a sus muertos (Musters 2005 [1911]: 211; Schmid 1964:184), para rellenar sus armaduras (Musters 2005 [1911]: 200), como cintas para el pelo y para las botas de montar, y como fajas para sostener las mantas de pieles, como se ha mencionado.

La información etnográfica que proporciona Millán de Palavecino y que fue recabada hacia la década de 1960, resulta reveladora: después de analizar junto a una tejedora «tehuelche» (Agustina Kilchamall) numerosas piezas textiles antiguas correspondientes a las parcialidades araucanas y «tehuelches», esta autora determinó que los dibujos reconocidos por su asistente como propios de su cultura sólo estaban presentes en los tejidos empleados en la actividad ecuestre, tales como las matras, matrones, caronillas y fajas (estas últimas, como dijimos, empleadas como vestimenta y a la vez como estribo por las mujeres) y no se hallaban en otros tipos de prendas tejidas (Millán de Palavecino 1963: 427) ${ }^{10}$.

\section{Síntesis, conclusiones y propuesta}

Hasta el momento existen dos hipótesis vigentes acerca de las razones por las cuales los aónik'enk adoptaron la textilería: la primera de ellas sostiene que fue debido a la carencia de pieles después del asentamiento de las estancias en Patagonia; la segunda afirma en forma indirecta que fue la disponibilidad de ganado ovino. Desde un punto de vista histórico, ambos supuestos implican que la adopción de la textilería por los aónik'enk se habría producido hacia finales del siglo XIX. Desde un punto de vista lógico, suponen que la adopción de la práctica textil y también la ausencia de su adopción fueron el resultado de una situación de escasez: la primera, supone la escasez de cueros; la segunda, supone la escasez de ganado ovino. Ello implica, a su vez, que la adopción o no adopción de la textilería por los aónik'enk estuvieron determi-

\footnotetext{
10 A través de sus investigaciones, Millán de Palavecino pudo determinar que los temas decorativos de los textiles pampeanos y patagónicos eran propios de cada parcialidad (1963). Un reciente estudio sobre los diseños textiles en las comunidades tehuelches y mapuches del centro-norte de la provincia de Chubut permite corroborar esta afirmación y agregar que dicha particularidad se conserva en esa zona en la actualidad (Finkelstein et. al. 2010).
} 
nadas por el entorno material, es decir, por la disponibilidad de pieles y de ovejas. De esta manera, el medio material se presenta como determinante del cambio cultural.

Sin embargo, la información empírica permite cuestionar y relativizar esas hipótesis. En primer lugar, los testimonios hallados refieren que algunos aónik'enk realizaban tejidos un siglo antes de lo supuesto hasta el momento; en segundo lugar, esa actividad textil se encuentra presente entre algunos aónik'enk en momentos en que éstos contaban con disponibilidad de caza $-\mathrm{y}$ la posibilidad de conseguir pieles- y no disponían aún de ganado ovino. Por lo tanto, la adopción de la textilería por los aónik'enk es más antigua de lo supuesto hasta el momento y no fue necesariamente el resultado de una situación de escasez: ciertos grupos tuvieron la posibilidad de elegir la adopción o no de esa práctica. Algunos de ellos adoptaron el arte textil a pesar de contar con las materias primas (pieles) para elaborar sus utensilios, hogar y vestimenta tal como lo habían hecho durante siglos. Otros no lo adoptaron a pesar de contar con los medios necesarios para desarrollarla, tales como el pelo de guanaco y más adelante, la lana. De ello se deduce que ni la escasez de medios ni las condiciones materiales pueden establecerse a priori como limitantes del desarrollo de la textilería entre los aónik'enk. Asumiendo esta lógica sería posible afirmar que la carencia de árboles de donde obtener los palos adecuados para los telares habría impedido la adopción de la textilería. Sin embargo, se ha visto que no fue así.

Polanyi (1976) ha propuesto que la lógica de la escasez de los medios con relación a los fines es una situación que se presenta en una economía de mercado pero que no debe extenderse a priori a otras formas de organización. Puede existir elección de medios sin insuficiencia (cuando la elección es inducida por consideraciones morales) e insuficiencia de medios sin elección (cuando la escasez es tal que no hay posibilidades de elegir). Siguiendo su planteamiento Sahlins ha afirmado: «La escasez es el juicio dictado por nuestra economía y, por lo tanto, también el axioma que rige nuestra Economía [...] Habiéndole atribuido al cazador impulsos burgueses y herramientas paleolíticas juzgamos su situación desesperada por adelantado» (Sahlins 1988: 17).

En otro trabajo se planteó la posibilidad de que la adopción de la práctica textil por los aónik'enk estuviese relacionada con la incorporación de la actividad ecuestre. Como se ha mencionado aquella fue adoptada por algunos aónik'enk aproximadamente un siglo después -o probablemente menos- de la incorporación de los equinos a su vida. Y los textiles que ellos realizaron fueron los vinculados a la actividad ecuestre. A partir de ello se conjeturó que la práctica ecuestre habría sido un estímulo para el desarrollo de la textilería (Méndez 2010). Sin embargo el análisis empírico aquí presentado muestra que algunos aónik'enk fueron ecuestres y no practicaron la textilería o la adoptaron sólo un par de siglos después, con lo cual la incorporación de los equinos tampoco explica la adopción de la textilería por los aónik'enk.

Se estima que esta falencia explicativa reside en que esta hipótesis, al igual que las revisadas en este trabajo, encuentra exclusivamente en el entorno material las posibles razones de la adopción de la práctica textil y por lo tanto supone que las condiciones materiales organizan la cultura o, expresado de otra manera, que la cultura está subordinada a lo instrumental o material. En este sentido, las hipótesis analizadas tienen un denominador común con gran parte de los estudios arqueológicos sobre los indígenas de la Patagonia argentina y a los que se han referido del Castillo Bernal, 
Mameli y Barceló (2011). Según estos autores, en esos estudios las interpretaciones de los fenómenos sociales «sólo tienen en consideración los cambios ambientales, el crecimiento demográfico y determinismos geográficos y/o económicos [...] Las descripciones arqueológicas de los grupos humanos patagónicos han sido reducidas a la relación hombre-medioambiente, entendidas éstas desde una perspectiva funcional que concibe la economía en términos de la optimización de las adaptaciones de las comunidades, las cuales se adaptan a ecosistemas particulares [...]» (Castillo et al. 2011: 40, 43).

Como alternativa se propone adoptar una perspectiva diferente para el análisis que comparte el principio o supuesto planteado por esos autores. Ellos afirman: «El fundamento de nuestro enfoque es que decisiones [de] las que derivan cambios visibles arqueológicamente fueron socialmente mediadas y no ecológica o ambientalmente impuestas» (2011: 44). Aquí se propone que los cambios culturales (visibles en los documentos escritos) son culturalmente mediados y no ecológica o materialmente determinados.

Como se ha planteado, los aónik'enk mantuvieron el quillango como vestido principal; y aquellos que adoptaron la textilería sólo confeccionaron tejidos que usaron en la actividad ecuestre (principalmente en las cabalgaduras de las mujeres, aunque no exclusivamente), a los cuales también les dieron otros usos y en los que plasmaron sus diseños característicos. En cuanto a las restantes prendas de vestir, éstas podían tener diferentes orígenes: ser de manufactura criolla, europea o de otras agrupaciones indígenas.

Si adoptamos una interpretación simbólica de la cultura y asumimos que el «sistema significativo es lo que define toda funcionalidad» (Sahlins 1988: 204), es posible afirmar que los aónik'enk elaboraron sólo aquellos tejidos que resultaron adecuados para su «sistema significativo» o reglas de significación culturales. Esto implica considerar que las adopciones de elementos foráneos a una cultura $-\mathrm{y}$ por supuesto, las innovaciones- son el resultado de selecciones realizadas a partir de evaluaciones acerca de la conveniencia o no de esas incorporaciones que actúan en función de los valores del grupo. Esos intereses y valores llevan a elegir, de entre los variados rasgos de las culturas con las que se entra en contacto, aquellos que resultan adecuados a su cultura, y esta selección puede resultar fútil e incluso incoherente desde el punto de vista de un foráneo. Las hipótesis que se han analizado en este trabajo resultan lógicas a determinado modo de entender la realidad, es decir, a partir de ciertos patrones de pensamiento; sin embargo, para otros esquemas de comprensión basados en valores diferentes ello puede resultar inaceptable (Benedict 1971) ${ }^{11}$.

Adoptar esta perspectiva no implica soslayar los condicionamientos materiales sino afirmar que el interés práctico de los hombres está construido simbólicamente o, en otras palabras, que la razón práctica está condicionada por la forma cultural (Sahlins 1988: 205). «Incluso en condiciones materiales muy similares, los órdenes y los fines culturales pueden ser bastantes disímiles. En efecto, las condiciones materiales, si bien siempre indispensables, son potencialmente 'objetivas' y 'necesarias'

11 El rechazo que los aborígenes pampeanos y patagónicos experimentaron por el consumo de cerdos (Palermo 1991: 162) o la resistencia de algunos grupos patagónicos al consumo de pescado (Musters 2005 [1911]: 142; Coan 2006 [1880]: 51) son algunos ejemplos que ilustran esta idea. 
de muchas maneras distintas, de acuerdo con la selección cultural por la cual se convierten en 'fuerzas' efectivas» (Sahlins 1988: 168).

Se estima que esta perspectiva permite formular explicaciones satisfactorias sobre por qué los aónik'enk realizaron algunos tejidos y no otros, y les dieron usos diferentes de los que les dieron sus vecinos. También permite plantear hipótesis alternativas para entender por qué algunos adoptaron la textilería a pesar de disponer de pieles, o de las dificultades para conseguir palos para los telares, o de los problemas ocasionados por el nomadismo, y por qué otros, en las mismas condiciones materiales, no lo hicieron. O por qué algunos aónik'enk no adoptaron la textilería en tiempos posteriores a pesar de disponer de los medios materiales necesarios, como pelo de guanaco y lana.

Incluir a varios grupos indígenas bajo una única denominación (aónik'enk) puede dar la impresión de la existencia de un colectivo culturalmente homogéneo, cuando en realidad no es así. Al igual que otras agrupaciones de Pampa y Patagonia, bajo una misma identificación es posible hallar parcialidades culturalmente diferenciadas, es decir, con diversos «órdenes significativos de personas y cosas» (Sahlins 1988: 11) ${ }^{12}$. Resulta plausible, entonces, que hayan existido diferencias en los intereses y valores de las parcialidades aónik'enk que llevaron a que algunas adoptaran la textilería y otras no lo hicieran.

Para finalizar, y siguiendo a Benedict (1971), se estima que si se adopta este marco teórico, es decir, si se supone que todo elemento cultural se define a partir de patrones coherentes de acuerdo con las reglas (conscientes e inconscientes) de selección que se desarrollan dentro de la misma cultura, y se pretende conocer las razones por las cuales algunos aónik'enk adoptaron la textilería y las causas de las características que adoptó entre ellos, es necesario poner esas cuestiones en relación con los valores instituidos en esos grupos y con los intereses que pueden estar relacionados con sus diversas actividades y el ambiente. Un objetivo que queda planteado para futuras investigaciones.

Agradecimientos: Agradezco a Julieta Gómez Otero y a Adrián Koberwein las colaboraciones y observaciones realizadas al presente artículo.

\section{Referencias bibliográficas}

BARNE, Jorge

1837 «Viage que hizo el San Martín, desde Buenos Aires al Puerto de San Julián, el año de 1752», en Colección de viages y expediciones a los campos de Buenos Aires y a las costas de Patagonia, Pedro De Angelis comp., tomo 2. Buenos Aires: Imprenta del Estado.

\footnotetext{
12 Como ejemplo, las diferentes parcialidades selk'nam otorgaron significaciones distintas a la adopción de la vestimenta foránea por parte de algunos de sus integrantes o a la residencia de ellos entre los colonizadores a comienzos del siglo XX, lo cual llevó a la aceptación de esas prácticas por parte de algunos grupos y al rechazo de ellas por parte de otros (Belza 1974: 344).
} 
BeLzA, Juan

1974 En la isla del fuego. Tomo 1. Buenos Aires: Instituto de Investigaciones Históricas Tierra del Fuego.

BENEDICT, Ruth

1971 El hombre y la cultura. Buenos Aires: Centro Editor de América Latina.

BoAs, Franz

1964 Cuestiones fundamentales de Antropología Cultural. Buenos Aires: Solar - Hachette.

CasamiQuela, Rodolfo

1965 Rectificaciones y ratificaciones. Hacia una interpretación definitiva del panorama etnológico de la Patagonia y área septentrional adyacente. Bahía Blanca: Universidad Nacional del Sur.

Casamiquela, Rodolfo, Osvaldo Mondelo, Enrique Perea y Mateo Martinic Berós

1991 Del Mito a la realidad. Evolución iconográfica del pueblo Tehuelche Meridional. Buenos Aires: Fundación Ameghino.

Castillo, Agustín del

1979 Exploración de Santa Cruz y Costas del Pacífico. Buenos Aires: Marymar.

Castillo Bernal, Florencia del, Laura Mameli y Joan Barceló

2011 «La arqueología patagónica y la reconstrucción de la historia indígena». Revista Española de Antropología Americana 41 (1): 27.50.

Caviglia, Sergio

2003 «El arte de las mujeres aónik’enk y gününa küna: kay guaj’enk o kay gütrruj (las capas pintadas)». Relaciones de la Sociedad Argentina de Antropología 27: 41-77.

Chertudi, Susana y Ricardo NARDI

1961 «Tejidos Araucanos de la Argentina». Cuadernos del Instituto Nacional de Investigaciones Folklóricas 2: 97-182.

Claraz, Georges

2008 Viaje al río Chubut. Buenos Aires: Ediciones Continente.

CoAn, Titus

2006 Aventuras en Patagonia. Un viaje de exploración de dos misioneros norteamericanos, Noviembre 1833 - Marzo 1834 [1880]. Buenos Aires: Zagier \& Urruty Publications.

Cordoba, Antonio de

1788 Relación del último viage al Estrecho de Magallanes de la Fragata de S. M. Santa María de la Cabeza en los años de 1785 y 1786 . Madrid: Viuda de Ibarra, Hijos y Compañía.

Cox, Guillermo

1999 Viaje en las regiones septentrionales de la Patagonia, 1862-1863 [1863]. Santiago de Chile: Imprenta Nacional.

Escalada, Federico

1949 El complejo tehuelche. Estudios de etnografía patagónica. Buenos Aires: Imprenta y casa editora Coni. 
FIADONE, Alejandro

2007 Simbología mapuche. Buenos Aires: Maizal Ediciones.

FinKelstein, Débora

2008 «Artesanías de alta Calidad con diseños basados en la cultura e identidad comarcal». Consejo Federal de Inversiones. Informes finales de trabajo: agosto de 2006, febrero de 2007, febrero de 2008.

Finkelstein, Débora, Patricia Méndez y María Marta Novella

2010 Informe de investigación sobre los diseños textiles en la Comarca de la Meseta Central de la provincia de Chubut para la Secretaría de Ciencia y Técnica del Ministerio de Educación.

Fitz Roy, Robert

1839 Narrative of the surveying voyages of his majesty's ships Adventure and Beagle between the years 1826 and 1836. Volumen 1. Londres: J. L. Cox and Sons.

Gómez Otero, Julieta

s/f «Las artesanías tehuelches y su evolución desde 1520 hasta comienzos del siglo XX. Primera Parte».

GonZÁLEZ, Francisco

1965 Diario del viaje que hizo por tierra de Puerto Deseado al río Negro. 1798. Buenos Aires: Academia Nacional de la Historia.

HADJUK, Adam

1981-82 «Algunos antecedentes arqueológicos de los mapuche en la Argentina», en Cultura Mapuche en la Argentina, pp. 7-29. Buenos Aires: Instituto Nacional de Antropología.

HARRIS, Marvin

1996 El desarrollo de la teoría antropológica. Historia de las teorías de la cultura [1979]. México: Siglo Veintiuno.

HATCHER, John

2003 Cazadores de huesos en la Patagonia. Ushuaia: Zagier y Urruty Publications.

Irusta De BenBassat, Delia

1986 Trabajo de campo Area Educativa Gastre (DPC-CPE). Informe para el Departamento de Investigación y Conservación de la Dirección de Cultura de la Provincia de Chubut.

KERMES, Enrique

1893 «Tejidos Pampas». Revista del Jardín Zoológico de Buenos Aires 1 (4): 178-187.

LisTA, Ramón

1879 Viaje al país de los Tehuelches. Exploraciones en la Patagonia Austral. Buenos Aires: Imprenta de Martín Biedma.

1975 Mis exploraciones y descubrimientos en la Patagonia, 1877-1880 [1881]. Buenos Aires: Marymar.

Lorenzo, José, Gonzalo Murga y Martín Ferreiro

1864 Diccionario Marítimo Español. Madrid: Establecimiento Tipográfico de T. Fortanet. 
MANDRini, Raúl y Sara ORTELli

2006 «Las fronteras del Sur», en Vivir entre dos mundos. Las fronteras del sur de la Argentina. Siglos XVIII y XIX, Raúl Mandrini, ed., pp. 21-42. Buenos Aires: Nueva Dimensión Argentina.

MARí, Jorge y Enrique TARANTO

2001 Textiles de uso tradicional. Buenos Aires: Asociación Criolla Argentina.

MARTINIC, Mateo

1995 Los Aónikenk, historia y cultura. Punta Arenas: Ediciones Universidad de Magallanes.

MÉnDEZ, Patricia

2009a «Herencia textil, identidad indígena y recursos económicos en la Patagonia Argentina». AIBR, Revista de Antropología Iberoamericana 4 (1): 11-53.

2009b «Los tejidos indígenas en la Patagonia Argentina: cuatro siglos de comercio textil». Indiana 26: 233-266.

2010 «El arte textil aónik’enk: posibles modos de adopción y algunas particularidades». Magallania 38 (2).

Mendoza, Doroteo

1965 Diario y memoria del viaje al Estrecho de Magallanes 1865-1866. Buenos Aires: Academia Nacional de la Historia.

Millán de Palavecino, María Delia

1932 «Tejidos araucanos del Neuquén», en $X X V^{\circ}$ Congreso Internacional de Americanistas realizado en la Universidad Nacional de La Plata (Buenos Aires) en 1932, pp. 215-222. Universidad Nacional de La Plata.

1963 «Área de expansión del tejido araucano», en Primer Congreso del Área Araucana Argentina realizado en San Martín de los Andes (Neuquén) del 18 al 24 de Febrero de 1961, pp. 411-448. Buenos Aires.

Moreno, Francisco

1969 Viaje a la Patagonia Austral [1879]. Buenos Aires: Solar - Hachette.

Musters, George

2005 Vida entre los Patagones [1911]. Buenos Aires: El Elefante Blanco.

OnELLi, Clemente

1916 Alfombras y tapices. Tejidos criollos. Buenos Aires: Ediciones Guillermo Kraft.

1977 Trepando Los Andes [1904]. Buenos Aires: Ediciones Marymar.

Palermo, Miguel Ángel

1991 «La compleja integración hispano-indígena del sur argentino y chileno durante el período colonial». América Indígena 51 (1): 153-192.

1994 «Economía y mujer en el sur argentino». Memoria Americana 3: 63-90.

1999 «Mapuches, Pampas y mercados coloniales». Etnohistoria. CD-Rom editado por NAyA.

PÉrez de Micou, Cecilia

2009 «Tejidos para la vida y la muerte. Prendas textiles en el Alero Mazquiarán», en Investigaciones multidisciplinarias en Río Mayo, Chubut, Patagonia argentina, Cecilia Pérez de Micou, Matilde Trivi de Mandri y Lidia Burry, comps., pp. 81-92. Buenos Aires: Fundación de Historia Natural. 
Polanyi, Karl

1976 «El sistema económico como proceso institucionalizado», en Antropología y economía, Maurice Godelier, comp., pp. 155-178. Barcelona: Editorial Anagrama.

SAHLINS, Marshall

1988 Cultura y razón práctica. Contra el utilitarismo en la teoría antropológica [1976]. Madrid: Editorial Gedisa.

SCHMID, Teófilo

1964 Misionando por la Patagonia Austral. 1858-1865. Buenos Aires: Academia Nacional de la Historia.

Viedma, Antonio de

1837 «Diario de un viage a la costa de Patagonia para reconocer los puntos donde establecer poblaciones», en Colección de obras y documentos relativos a la historia antigua y moderna de las provincias del Río de la Plata, Pedro De Angelis, comp., Tomo 6. Buenos Aires: Imprenta del Estado.

VIEDMA, Francisco de

1938 «Informe al Virrey Vértiz, del 13 de Octubre de 1783». Revista de la Biblioteca Nacional 2 (7): 588-602.

Vignati, Milcíades

s/f «Etnografía y Arqueología. Usos, costumbres y cultura de los aborígenes de Buenos Aires, La Pampa y Patagonia: Período Colonial», en Historia Argentina, Tomo 5. Buenos Aires: Plaza y Janés S.A. 